\title{
"Success Judokas" - The construction process of the Portuguese Long- Term Judo Development Model
}

\author{
Francisco SILVA*1, Rui VIEIRA ${ }^{1}$, Nuno DELGADO ${ }^{1}$, José Mário CACHADA ${ }^{1,2}$, \& Bruno AVELAR- \\ ROSA $1,3,4$ \\ ${ }^{1}$ Portuguese Judo Federation (Portugal) \\ ${ }^{2}$ Faculty of Sport, University of Oporto (Portugal) \\ ${ }^{3}$ Europeia University (Portugal) \\ ${ }^{4}$ University of Girona (Spain)
}

5th IMACSSS World Scientific Congress Abstracts, Rio Maior (Portugal), October 6-8

Section: Coaching, training and health issues in MA\&CS

Type: Oral communication

\section{Introduction}

The current coach education model associates coaching qualification level's profiles with athlete's development stages (Trudel \& Gilbert, 2006; Duffy, 2008; Sports Coach UK, 2009; ICCE, 2012). One example is the Long Term Athlete Development (LTAD) (Balyi, et al., 2014): "LTAD is a training, competition and recovery program based on developmental age - the maturation level of an individual - rather than chronological age. It is athlete-centred, coach driven and administration, sport science and sponsor supported" (Balyi, et al., 2014, p.15).

Despite some critic assumptions (Ford, et al., 2011), the LTAD model it's an important benchmark in the implementation of athletes training programs and in coach education frameworks, in many countries and sports. In the Judo case the first LTAD model proposals were made by the Canadian Judo Federation (2006) and by the British Judo Association (2006). In order to keep up with the most innovative trends and best practices in athletes and coach's developmental programs, the Portuguese Judo Federation (PJF) started to develop its own Judokas preparation model ("Success Judokas"), based in the principles of the LTAD model, but adapting it the Portuguese Judo reality. This text addresses the used methodology for the construction model of "Success Judokas", and the main results of its first phase.

\section{Methodology}

To develop the model for "Success Judokas" a team of six experts was created. All of the team elements were Judo coaches with an academic degree in sports; combining elements that had an extensive experience in Judo training, at different ages and levels, with elements that had research experience in the area. The team was responsible for the methodological process definition, the validation of the used instruments, and the data collection procedures, based on a qualitative methodology research (Flick, 2007).

The building process of the "Success Judokas" model stimulates the participation of national Judo coaches, considering their experience and knowledge of their own Judo athletes. The coaches participated in three workshops (in the north, center and south of the country), with the aim to discuss different ideas, using a focus group approach, related with five issues:

1. The relevance of creating and adopting a judokas preparation model in Portugal;

2. The identification and characterization of the athletes' development stages;

*Email: francisco.silva@ipdj.pt 
3. The type, frequency and duration of Judo training in each stage;

4. The importance of competition in defining goals, planning and orientation training;

5. The identification of technical and tactical priorities for each stage.

These workshops were attended by about $15 \%$ of the Portuguese coaches (17 coaches in the north, 37 in the center and 23 in the south), selected and invited by the regional judo organizations, according their suitability for designated tasks.

\section{Results}

According each issue, the following trends were identified: (1) It is recognized the relevance of having a reference model to serve coaches intervention in each development stage; (2) A large majority of coaches proposes a 6 stages model divided in the following age groups: $3 / 4$ to $6 / 5$ years old; $6 / 7$ to $8 / 9$ years old; $9 / 10$ to $11 / 12$ years old; $12 / 13$ to $14 / 15$ years old; $15 / 16$ to $17 / 18$ years; From 18/19 years old; (3) The average number of hours/week dedicated for Judo training should be progressive and goes from about $1 \mathrm{~h} 45 \mathrm{~m}$ in stage 1 to $10 \mathrm{~h}$ in step 6; (4) Participation in competition is considered a key factor in the development of judoka and has a more important role in the planning and training process at the advanced stages of the athlete career (5). The priorities of the technical and tactical training throughout the judoka career varies from the introduction and development of a wide range of throwing and holding techniques, with emphasis on multidirectional movement in the early stages (1-3), to an increasing focus on the development of specialization of own techniques, with emphasis on specific competition skills and tactics between steps 4 and 6.

\section{Final notes}

After the first phase contributions, the process of the "Success Judokas" model construction raises a new round of discussions, where the results obtained are presented, in order to adjust the objectivity and applicability of its contents. Finally, the proposed institutional model "Success judokas" will be ready to be published by PJF, permitting national coaches to implement it on their athletes.

\section{References}

Balyi, I., Cardinal, C., Higgs, C., Norris, S., \& Way, R. (2014). Canadian Sport for Life - Long-Term Athlete Development Resource Paper 2.0. Vancoucer: Canadian Sports Centres.

British Judo (2006). Long-Term Player Development - British Judo. Loughsborough: British Judo Association.

Duffy, P. (2008) Implementation of the Bologna Process and Model Curriculum Development in Coaching. In K. Petry, K. Froberg, \& A. Madella (Eds.). Higher Education in Sport in Europe. From labour market demand to training supply (pp. 80-108). Maindenhead: Meyer \& Meyer Sport.

Flick, W. (2007). Introducción a la Investigación Cualitativa. Madrid: Morata.

Ford, P., de Ste. Croix, M., Lloyd, R., Meyers, R., Moosavi, M., Oliver, J., Till, K., \& Williams, C. (2011). The Long-Term Athlete Development model: Physiological evidence and application, Journal of Sports Sciences, 29(4), 389-402.

ICCE (2012). International Sport Coaching Framework - version 1.1. Champaign: Human Kinetics.

Judo Canada (2006). Taking it to the Mat - Long-Term Athlete Development Judo. Vancouver: Judo Canada.

Sports Coach UK (2009). The UK Coaching Framework - The Coach Development Model - User Guide. Leeds: Sports Coach UK.

Trudel, P., \& Gilbert, W. (2006). Coaching and coach education. In D. Kirk, M. O'Sullivan, \& D. McDonald (Eds.), Handbook of Physical Education (pp. 516-539). London: Sage.

Key words: Coach education; long-term Judo development; Judo methodological stages. 